\title{
Comparison of Neural Response Telemetry (NRT) results of cochlear implanted children in view of pre-operative Auditory Brainstem Response (ABR)
}

Selim Unsal ${ }^{1 *}$

Mehmet Gunduz ${ }^{2}$

\begin{abstract}
Objective: To compare the Neural Response Telemetry (NRT) results of the cochlear implanted children who showed wave 5 and who could not, in preimplantation ABR.

Material and method: 24 children (11 boys, 13 girls) with bilateral profound sensorineural hearing loss participated in this study. Age of children ranged between 13 and 60 months (mean 30 months). All participated children were implanted with Cochlear ${ }^{\circledR}$ Nucleus brand devices. In preoperative ABR evaluation with click stimulus in $100 \mathrm{dBnHL}$ intensity level, 9 children showed wave $\mathrm{V}$ and 15 children did not. We compared intraoperative NRT results of $1^{\text {st }}, 6$ th $, 11^{\text {th }}, 16^{\text {th }}$ and $22^{\text {nd }}$ electrodes, those were selected from 22 electrodes, of the two groups.

Results: There was no statistically significant difference between the children who showed wave $V$ and who did not in preoperative ABR, when compared the intraoperative NRT results of $1^{\text {st }}, 6^{\text {th }}, 11^{\text {th }}, 16^{\text {th }}$ and $22^{\text {nd }}$ electrodes $(p>0,05)$.

Conclusion: intraoperative NRT was obtained in all the implanted children with bilateral profound sensorineural hearing loss, even if they received wave $\mathrm{V}$ or not in preoperative ABR. There was no difference between any of the parameters of the test results of the two groups. Normal NRT results can be achievable when there is no wave $\mathrm{V}$ in preoperative $\mathrm{ABR}$.
\end{abstract}

Keywords: Cochlear implant, NRT, ABR. 


\section{INTRODUCTION}

Cochlear implant is a complex device that can be placed surgically to the children and adults, who have bilateral profound sensorineural hearing loss and could not benefit from hearing aids ${ }^{1-3}$. Electrodes are placed in cochlea to stimulate the cochlear nerve and mimic the tonotopic organization of cochlea. Electrical impulse bypasses the damaged hair cells and directly stimulates the cochlear nerve fibers ${ }^{4}$. With this stimulation action potential is formed in the nerve fibers and perceived as the hearing sensation ${ }^{5-7}$. Neural Response Telemetry (NRT) is a method that directly measures the compound action potential in the cochlear nerve of the cochlear implant users ${ }^{8}$. This stimulation is the main purpose of the cochlear implant. Action potentials of the cochlear nerve can be measured in both intraoperative and postoperative period. In pediatric group, cochlear implant decision must be made with the complete audiological examination. Audiological evaluation includes immitansmetry, ipsi and contralateral acoustic reflexes, Otoacoustic Emissions (OAE), free field evaluations and Auditory Brainstem Response (ABR) ${ }^{9}$ 11. Wave $V$ cannot be achieved in those who have severe or profound sensorineural hearing loss in ABR test. This situation may cause a negative impression such as, the one cannot benefit from cochlear implant when deciding implantation. We aimed to show action potential in the Neural Response Telemetry (NRT) of the cochlear implanted pediatric group patients who could not show wave $V$ in pre implantation $A B R^{12}$.

\section{MATERIALS AND METHODS}

This study was carried out in Turgut ozal University Hospital, ENT Department. All cochlear implant candidate children underwent complete audiological evaluation after full physical examination ${ }^{13}$. Twenty four children (11 boys, 13 girls) with bilateral profound sensorineural hearing loss participated in this study. Age of children ranged between 13 and 60 months (mean 30 months) ${ }^{14}$. All participated children were implanted with Cochlear ${ }^{\circledR}$ Nucleus brand devices. In preoperative ABR evaluation click stimulus was used in $100 \mathrm{dBnHL}$ intensity level, and 9 children showed wave $V$ and 15 children did not. We compared intraoperative NRT results of $1^{\text {st }}, 6^{\text {th }}, 11^{\text {th }}$, $16^{\text {th }}$ and $22^{\text {nd }}$ electrodes, those were selected from 22 electrodes, of the two groups. Mann Whitney $U$ test was used to compare the NRT results of the cochlear implanted children who showed wave 5 and who could not, in ABR test made in the preoperative period. Differences were considered significant when $p$ value was 0.05 or less ${ }^{15-17}$.

\section{RESULTS}

NRT results of the cochlear implanted children who showed wave 5 and who could not, in preimplantation
ABR, were shown in Table 1 and Table 2. Intraoperative NRT results derived from 5 electrodes $\left(1^{\text {st }}, 6^{\text {th }}, 11^{\text {th }}\right.$, $16^{\text {th }}$ and $22^{\text {nd }}$ electrodes) of the cochlear implanted children who showed wave 5 and who could not, in preimplantation $\mathrm{ABR}$, were evaluated and compared. The two groups did not show statistically significant difference regarding NRT results $(p>0,05)$ (Figure 1 and Figure 2).

Table 1: NRT results of the children who showed wave $V$ in $A B R$.

\begin{tabular}{cccc}
\hline Electrode & Min $\mu \mathbf{V}$ & Max $\mu \mathbf{V}$ & Mean \pm SD \\
\hline $22^{\text {nd }}$ electrode & $159 \mu \mathrm{V}$ & $184 \mu \mathrm{V}$ & $169,29 \pm 9,742$ \\
$16^{\text {th }}$ electrode & $173 \mu \mathrm{V}$ & $197 \mu \mathrm{V}$ & $181,71 \pm 9,979$ \\
$11^{\text {th }}$ electrode & $181 \mu \mathrm{V}$ & $200 \mu \mathrm{V}$ & $188,29 \pm 5,823$ \\
$6^{\text {th }}$ electrode & $142 \mu \mathrm{V}$ & $193 \mu \mathrm{V}$ & $174,00 \pm 19,391$ \\
$1^{\text {st }}$ electrode & $160 \mu \mathrm{V}$ & $202 \mu \mathrm{V}$ & $196,86 \pm 23,822$ \\
\hline
\end{tabular}

Table 2: NRT results of the children who could not show wave $\mathrm{V}$ in ABR.

\begin{tabular}{cccc}
\hline Electrode & Min $\mu \mathbf{V}$ & Max $\mu \mathbf{V}$ & Mean \pm SD \\
\hline $22^{\text {nd }}$ electrode & $146 \mu \mathrm{V}$ & $192 \mu \mathrm{V}$ & $171,00 \pm 14,091$ \\
$16^{\text {th }}$ electrode & $160 \mu \mathrm{V}$ & $213 \mu \mathrm{V}$ & $183,53 \pm 13,768$ \\
$11^{\text {th }}$ electrode & $161 \mu \mathrm{V}$ & $214 \mu \mathrm{V}$ & $190,40 \pm 17,553$ \\
$6^{\text {th }}$ electrode & $163 \mu \mathrm{V}$ & $218 \mu \mathrm{V}$ & $192,87 \pm 15,928$ \\
$1^{\text {st }}$ electrode & $175 \mu \mathrm{V}$ & $234 \mu \mathrm{V}$ & $207,33 \pm 16,804$ \\
\hline
\end{tabular}

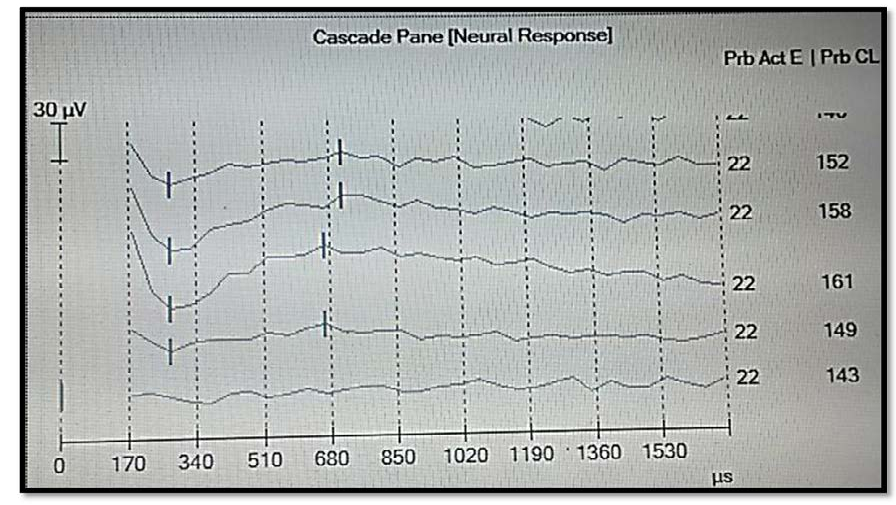

Figure 1. NRT result of a child who showed wave $V$ in $A B R$.

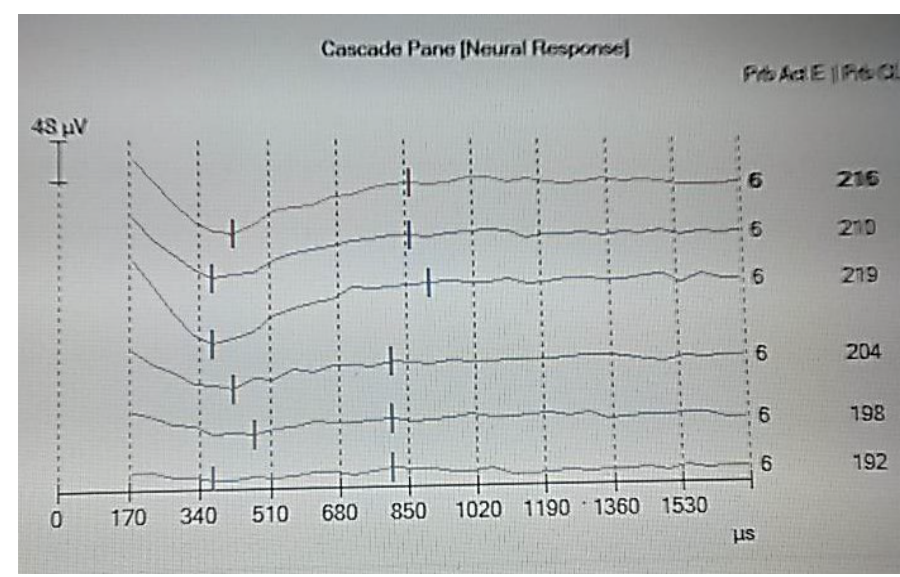

Figure 2. NRT result of a child who could not show wave $V$ in ABR. 


\section{DISCUSSION}

Measurement of action potentials that occur in the auditory nerve is an important factor in terms of demonstrating the success of cochlear implants. Action potential of the cochlear nerve caused by cochlear implant is measured by all cochlear implant manufacturers and play a basic role in implant fitting. For recording and measuring the action potential of the cochlear nerve created by cochlear implant, Cochlear ${ }^{\circledR}$ company named the firmware as Neural Response Telemetry (NRT), Advanced Bionics ${ }^{\circledR}$ company named as Neural Response Imaging (NRI) and Med-EI ${ }^{\circledR}$ company named as Auditory Nerve Response Telemetry (ART). In our study, we obtained and compared intraoperative NRT results of 22 children who underwent cochlear implantation using Cochlear ${ }^{\circledR}$ Nucleus model implant and did not find any difference between NRT results. While it was not statistically significant, mean NRT values increased from apical to basal of the cochlea. NRT's being a measurement which facilitates programming of the speech processor in pediatric cochlear implant users is the most important role in clinical practice. In many studies, correlation was shown between NRT and thresholds using to program speech processor. Mean NRT thresholds of the apical electrodes were found lower than the medial and basal electrodes. Reduced NRT thresholds despite the less number of spiral ganglion of the apical region is attributed to narrow structure and therefore closer location of the electrode to modiolus and spiral ganglion showed that NRT thresholds in apical region is lower. In view of these NRT results, when determining the Threshold level (T level) in programming implant it can be said that real thresholds of the basal electrodes are higher than medial and apical electrodes, especially for the patients who showed no response in ABR test. NRT levels in programming are between threshold/comfort (T/C level) levels, in some researches it is above the $\mathrm{C}$ level.

\section{CONCLUSION}

Results of NRT testing can be used in cochlear implant programming. In children appropriate cochlear implant programming is extremely important. In adults, behavioral results and satisfaction rating can be obtained but they can be rarely achieved in children. For this reason, objective parameters should be obtained by using NRT and have to be used to determine $\mathrm{T} / \mathrm{C}$ levels. Identification of NRT thresholds of apical, medial and basal regions and using them in programming is important in appropriate programming. Lower NRT thresholds in apical region and increase through basal region should be taken into account and $\mathrm{T} / \mathrm{C}$ levels should be programmed according to this. ABR test have an important role in cochlear implant decision and should be performed in all the children. The absence of wave $V$ does not have negative effect on cochlear implantation

\section{CONFLICT OF INTEREST}

The author declares no conflict of interest.

\section{REFERENCES}

1. Abbas PJ, Brown CJ, Shallop JK, Friszt JB, Hughes ML, Hong $\mathrm{SH}$, et al. Summary of Results Using the Nucleus Cl24M Implant to Record the Electrically Evoked Compound Action Potential. Ear Hearing. 1999;20:45-59.

2. Batman AC. Surgical techniques in cochlear implantation. Turkish Clinics, J ENT-Special Topics. 2012;5:12-20.

3. Brown CJ, Abbas PJ, Gantz B. Preliminary experience with Neural Response Telemetry in the Nucleus CI24M cochlear implant. Am J Otol. 1998;19:320-7.

4. Brown CJ, Hughes ML, Luk B, Abbas PJ, Wolaver A, Gervais J. The Relationship Between EAP and EABR Thresholds and Levels Used to Program the Nucleus 24 Speech Processor: Data from Adults. Ear Hear. 2000;21:151-63.

5. Brown CJ, Johnson TA. Electrophysiologic Assessment of Hearing. Cummings Otolaryngology Head\&Neck Surgery, Elsevier $5^{\text {th }}$ Edition. 2010;3:1912-14.

6. Cullington $\mathrm{H}$. Preliminary neural response telemetry results. Br J Audiol. 2000; 34:131-40.

7. Dees CD, Dillier N, Lai WK, Wallenberg EV, Dijk BV, Akdas $F$, et al. Normative findings of electrically compound action potential measurements using the Neural Response Telemetry of the Nucleus Cl24M Cochlear implant system. Audiol Neurootol. 2005;10:105-16.

8. Franklin DJ, McCoy MJ, Martin GK, Lonsbury Martin BL. Test/retest reliability of distortion product and transiently evoked otoacoustic emissions. Ear Hear. 1992; 13:417-29.

9. Gordon KA, Papsin BC, Harrison RV. Toward a Battery of Behavioral and Objective Measures to Achieve Optimal Cochlear Implant Stimulation Levels in Children. Ear Hear. 2004;25:447-49.

10. Gordon KA, Papsin BC, Harrison RV. Auditory brain stern and midbrain development after cochlear implantation in children, Ann Otol Rhinol Laryngol Suppl. 2002;189:32-7.

11. Hang AX, Kim GG, Zdanski CJ. Cochlear implantation in unique pediatric populations. Curr Opin Otolaryngol Head Neck Surg. 2012;20:507-17.

12. Hughes ML, Brown CJ, Abbas PJ, Wolaver AA, Gervais JP. Comparison of EAP thresholds with MAP levels in the Nucleus 24 cochlear implant: data from children. Ear Hear. 2000;21:164-74.

13. Incesulu SA. Cochlear implantation: Case selection criteria's in view of ENT and Audiology. Turkish Clinics, J ENT Special Topics. 2012;5:62-8.

14. Muhaimeed HA, Al Anazy F, Hamed O, Shubair E. Correlation between NRT measurement level and behavioral levels in pediatrics cochlear implant patients. Int J Pediatr Otorhinolaryngol. 2010;74:356-60.

15. Sebastian S, Sreedevi N, Lepcha A, Mathew J. Nasalance in Cochlear Implantees. Clin Exp Otorhinolaryngol. 2015;8:202-5.

16. Shallop KJ, Facer GW. Neural Response Telemetry with the Nucleus $\mathrm{Cl} 24 \mathrm{M}$ Cochlear Implant. Laryngoscope. 1999;109:1755-9.

17. Wang B, Cao K, Wei C. Cochlear implantation in patients with auditory neuropathy assisted by intra-operative EABR and the therapeutic effect evaluation. 2013;27:449-54. 